\title{
EL DERECHO DE LA PERSONA EN EUROPA HOY ${ }^{1}$
}

\author{
Ricardo de Angel Yágüez \\ Catedrático de Derecho civil de la Universidad de Deusto
}

1. Se adjudica a mi ponencia el título de «El Derecho de la persona en Europa hoy». Mucho me gustaría que, más que tener un carácter descriptivo, mi intervención pudiera formular algún vaticinio sobre el papel que la persona va a desempeñar en el Derecho civil del futuro. Pero hacer previsiones en Derecho es siempre sumamente aventurado. Cuando todavía hace sólo unos veinte años afirmábamos que una de las características del Derecho civil de entonces era su llamada «administrativización» (esto es, la creciente presencia de reglas de Derecho público en las relaciones inter privatos), no podíamos imaginar que en este final de siglo iba a desencadenarse la febril tendencia de «desregulaciones» - fruto a su vez del neoliberalismo, de las privatizaciones y de otros fenómenos que del primero traen causa- que hoy es signo de amplios sectores de la actividad económica y de su expresión jurídica.

Por eso, creo que no es tanto cuestión de hacer especulaciones sobre el mañana, sino de intentar describir los rasgos que me parecen más significativos del Derecho de la persona en el momento presente.

Por otro lado, el título atribuido a mi ponencia es demasiado ambicioso (hasta el punto de superar mis posibilidades), si lo que con ese epígrafe se busca es una descripción cabal de lo que en la materia que nos ocupa se observa en los ordenamientos más significativos de nuestro viejo continente. Por eso, forzoso es advertir que mi exposición versará sobre los rasgos actuales del Derecho de la persona en el ordenamiento español, en tanto en cuanto - según mis conocimientos- coincide con lo que ocurre en otros países europeos.

1 Se reproduce el texto de la conferencia inaugural pronunciada por el autor en el Congreso Internacional La persona y el Derecho en el fin de siglo, celebrado en Santa Fe, Argentina, del 24 al 26 de octubre de 1996. 
He de señalar, además, que mi aportación no se va a limitar al ámbito de lo que habitualmente conocemos como la responsabilidad civil o Derecho de daños, sino que procurará tomar como punto de partida los caracteres más salientes, ahora, de esa parcela del Derecho civil que conocemos como «Derecho de la persona».

2. A mi juicio, una forma de resumir el estado actual del Derecho de la persona en Europa es la de decir que refleja contrastes. Del mismo modo que hoy hablamos retrospectivamente de épocas de apogeo y de crisis del contrato, aunque refiriéndonos a momentos históricos sucesivos, ahora podría utilizarse ese binomio diciendo que, en efecto, el Derecho de la persona atraviesa por un momento de exaltación y, de otra parte, por una fase de declive.

Voy a tratar de ilustrar esta impresión (no me atrevo a darle otro nombre más científico) con algunas observaciones.

3. En primer lugar, puede afirmarse que el Derecho de la persona está conociendo un llamativo desarrollo.

Me refiero por ahora a datos puramente cuantitativos, por así decirlo, como los siguientes:

La bibliografía europea sobre la persona y los llamados derechos de la personalidad es abundantísima en los últimos tiempos. Basta echar una ojeada a los catálogos editoriales para fundar esta aseveración. Es notable el crecimiento, en proporción con otras materias de Derecho civil, de la que ahora nos ocupa.

De otra parte, en los tratados y manuales de Derecho civil es ostensible el incremento del apartado correspondiente al Derecho de la persona (según es habitual, en la parte general de Derecho civil), quizá en detrimento de temas que hemos considerado siempre más «clásicos» o propios de dicha parte general, como por ejemplo el derecho subjetivo y el negocio jurídico.

Por último, desde el punto de vista del Derecho positivo, los ordenamientos civiles europeos han dado entrada, bien por vía de sus códigos civiles, bien a través de leyes especiales, a una mayor atención a la persona. Se ha superado con creces su histórica reducción al estado civil o poco más; sobre todo, como consecuencia de la reglamentación de los derechos de la personalidad.

4. Todo ello, desde luego, no es una casualidad, sino que responde a profundas razones de fondo.

Ese fondo es la emergencia de los valores de la persona (señaladamente a partir de la Segunda Guerra Mundial) y, sobre todo, la reivindicación de una tutela jurídica para esos valores; esto es, superada ya la idea de otro tiempo de que sus vulneraciones sólo podían ser objeto de reproche moral. 
Es interesante poner de manifiesto que la inicial posición contraria a la «juridificación» de los derechos de la personalidad procedió, paradójicamente, de sectores que, por ser muy respetuosos hacia los valores individuales, consideraron que es indigno equipararlos a los meros intereses patrimoniales. Fue una tendencia del mundo jurídico anglosajón, pionero, por otra parte, de las libertades cívicas. Resulta significativa, por citar un ejemplo, la fundamentación de un fallo de la jurisprudencia norteamericana. Se trata de una sentencia de 1902, en la que se ventilaba la reclamación entablada por una señorita que demandaba a un fabricante de harina porque en los envases de su producto reproducía la fotografía de aquélla, desde luego muy púdica. El Tribunal desestimó la demanda de la ofendida, en la que ésta solicitaba una indemnización. El razonamiento de la sentencia giró en torno al pensamiento siguiente: «Hay muchas obligaciones que son demasiado delicadas y sutiles para ser puestas en vigor mediante el rudo método de indemnizarlas en caso de violación. Acaso los sentimientos ofendidos encuentran la mejor protección posible en el derecho moral y en una opinión pública favorable». En la declaración del Tribunal late una resignada afirmación sobre la impotencia del Derecho para hacer frente a situaciones que, precisamente por la dignidad de los valores puestos en juego, han de dejarse a un cumplimiento espontáneo y a una satisfacción estrictamente moral.

Incluso en los últimos tiempos, la «legalización» de los derechos de la personalidad ha suscitado alguna duda y hasta abiertos reproches. Se afirma, por ejemplo, que el respeto a los derechos de la personalidad depende del clima social imperante en cada país y que, en consecuencia, lo que en unos puede ser una política legislativa necesaria, en otros puede resultar contraproducente, en el sentido de crear de manera artificial problemas sociales antes desconocidos. De campos ajenos al Derecho procede el argumento de que no es conveniente que las normas jurídicas se interfieran en esta cuestión, dificultando la solución espontánea de los conflictos; que, evidentemente, es lo que constituye el desideratum desde un punto de vista estrictamente social. Algún autor ha llegado a invocar la teoría de que toda elaboración legislativa al respecto crea un clima de tal apasionamiento que las ventajas se ven superadas por los inconvenientes.

5. Pero, al margen de estas aisladas reticencias, es innegable que los últimos cuarenta o cincuenta años han conocido una vigorosa tendencia hacia la recuperación del valor central de la persona en el Derecho civil.

Es menester recordar que, al comienzo de esa época, una de las notas del Derecho civil fue la de su llamada «patrimonialización». Este fenómeno, sobre el que tan brillantemente escribió DIEZ-PICAZO en 1959, 
tuvo su origen en la corriente filosófica del racionalismo jurídico. Cuando se pierde, con la Reforma protestante, el enlace íntimo del Derecho civil con la concepción católica de la vida, inconscientemente quizá el hombre quedó aislado de su conexión con la Divinidad y de su conexión con la comunidad. Se rompió así el hilo sutil que enmarcaba a la persona, en todas sus dimensiones, dentro de la vida social. Esta soledad del ser humano daría lugar al racionalismo filosófico — pues sólo la razón del hombre es fuente de conocimiento-y al individualismo jurídico. La exaltación de los fines puramente materiales de la existencia, antes sometidos a los de carácter sobrenatural, hará aparecer la figura del homo oeconomicus. Por ello, como señalaba DIEZ-PICAZO, «nada tiene de extraño que el Derecho civil apareciese como el Derecho defensor de este tipo de fines, como el Derecho establecido para la realización de los fines económicos del hombre». De ahí la preeminencia del Derecho patrimonial o Derecho de bienes, desdibujándose aquellas partes del Derecho civil que contemplan fines de naturaleza distinta.

Y el mismo autor hizo una excelente síntesis con las siguientes palabras: «Coincidiendo con ello, la persona, su estado y su esfera jurídica desaparecen del sistema. Deja de existir un Derecho de la persona, para quedar ésta convertida en un puro valor instrumental: el de sujeto de una relación jurídica, casi siempre de carácter patrimonial. El estado y condición de la persona son contemplados como simples requisitos subjetivos de la relación jurídica. El poder la persona sobre su propia esfera jurídica (nombre, honor, buena fama, vida, integridad, pensamiento, etc.) están ausentes del Derecho civil. Al Derecho civil se le ha privado así de lo más sustancial que tenía. Pues si su función y su finalidad no es otra que la defensa de la persona y de sus fines, ésta, como primera realidad jurídica, habría de ser el centro del sistema».

También en la doctrina española, DE CASTRO había hecho notar, ya en los años 40, que los autores antiguos de Derecho civil apenas aludían a los derechos de la personalidad, fenómeno que el maestro explicaba por la tendencia especializadora de la ciencia jurídica, que trasladó esta materia al campo de la Teología moral, primero, y más tarde al Derecho público. Esta circunstancia permite entender, entre otras cosas, el silencio casi absoluto que los códigos de la familia del francés mostraron en relación con estos derechos.

También pudo contribuir a ese fenómeno, a mi juicio, el hecho de que hasta el siglo XVIII la persona se hallase filosófica y socialmente diluida en un marco en el que toda reacción defensiva se proyectaba en contra de un poder político absoluto. A partir de la Ilustración, la preocupación se centró en la formulación y salvaguardia de los derechos de la 
persona frente a ese poder, su máximo enemigo; y todos los logros se orientaron en el terreno de las libertades políticas.

Sólo cuando la persona consiguió un minimum de seguridad frente al poder, fue cuando sus preocupaciones se desplazaron al terreno de las relaciones privadas, en las que pronto empezaron a verse amenazados los valores más íntimos del individuo, colocado en una civilización que cada día - como dijo SAVATIER - se hacía más hostil para él.

Nació así un reacción defensiva, manifestada en una conciencia social sensible a los atentados contra la persona y sus cualidades. Y surgió, paralelamente, una mayor preocupación por los «derechos de la personalidad» en sentido estricto, materializada en un notable crecimiento de la bibliografía dedicada al tema y en la atención que le dedicaron códigos civiles como el italiano de 1942 o el portugués de 1967. En los trabajos preparatorios de la reforma del Código civil francés, tan abandonados que hoy son casi una cita histórica, la materia de los derechos de la personalidad era objeto de muy particular atención.

6. Ahora, como decíamos, el panorama es distinto. Se reclama para el Derecho civil la recuperación de su sentido histórico de Derecho dictado para la defensa y protección de la persona y para la realización de sus fines. El Derecho civil — se dice- puede ser un instrumento muy adecuado para poner coto a la excesiva injerencia estatal en la órbita de actuación de la persona y, contra el excesivo auge de los valores económicos, para recoger la totalidad de los fines de la persona y agrupar debidamente jerarquizadas las instituciones que los realicen.

Dicho de otro modo, la recuperación por el Derecho civil de los derechos de la persona se ha defendido con el siguiente razonamiento: si la regulación de todo lo referente a la persona y a los derechos personales se abandona a la competencia del Derecho público, estaremos minando nada más y nada menos que una de las materias más sagradas y tradicionales dentro del Derecho privado; se llegaría a poner en tela de juicio la razón de ser y la existencia misma del Derecho civil.

7. Particular relieve en este proceso ha tenido la doctrina de los llamados «derechos de la personalidad». Con este nombre se viene designando a una amplia y heterogénea serie de prerrogativas y poderes que garantizan a la persona el goce de las facultades del cuerpo y del espíritu o, dicho de otro modo, que aseguran al individuo el respeto a su personalidad física y moral.

La inquietud del Derecho civil por los derechos de la personalidad tiene su origen en el Derecho público, en concreto en la doctrina de los «derechos humanos». Estos, según la terminología comúnmente admitida, se desenvuelven en el plano de las relaciones individuo-Estado y ex- 
presan las libertades individuales que los poderes públicos no pueden menoscabar (o no pueden hacerlo sino de forma tasada, limitada y transitoria).

La transposición de los derechos humanos al campo del Derecho civil tiene su asiento en la observación de que también en el ámbito de las relaciones privadas los derechos de la persona exigen una tutela jurídica adecuada. En ese plano es donde hablamos de los «derechos de la personalidad», presentes en la doctrina del Derecho de la persona, en la del derecho subjetivo, en la de la autonomía privada $\mathrm{y}$, sobre todo, en sede de responsabilidad civil o Derecho de daños.

Antes de que por vía legal o jurisprudencial adquiriesen los derechos de la personalidad carta de naturaleza en el Derecho civil, la doctrina de los derechos humanos inspiró muchas de las propuestas formuladas para dar respuesta a conflictos entre particulares. Recuérdense las discusiones sobre si el Convenio europeo de salvaguarda de los derechos del hombre y de las libertades fundamentales (de Roma, 1950) vinculaba sólo a los Estatos contratantes o si alcanzaba también a los individuos situados bajo su jurisdicción. Esta segunda interpretación, la que otorga a los preceptos del Convenio una «eficacia absoluta», en el sentido de afectar a terceros (Drittwirkung), corresponde — según sostenían sus defensoresa las necesidades de nuestra época, protegiendo a los particulares contra sus semejantes y no sólo contra el poder público.

Esta fue, salvadas pequeñas distancias, la misma pregunta que se planteó a la luz de ciertos textos constitucionales que garantizan el ejercicio de las libertades individuales: han suscitado el problema de si son directamente aplicables a casos de vulneración por parte de las personas privadas o si, por el contrario, alcanzan tan sólo a las violaciones por parte del Estado o sus órganos. Es la cuestión acerca de lo que la doctrina alemana llamó Drittwirkung der Grundrechte (oponibilidad de los derechos fundamentales frente a las personas privadas), pregunta que en definitiva se inclinó en Alemania por la tesis afirmativa y que fue seguida también por la jurisprudencia de otros países.

El carácter ambivalente de los derechos humanos, en el sentido más amplio de la expresión (esto es, su manifestación en las relaciones individuo-Estado y su expresión en las relaciones individuo-individuo, esto último ya como «derechos de la personalidad»), se muestra de forma visible en muchas hipótesis. Esa doble faceta puede hacer que una misma «libertad» opere bajo el dominio del Derecho público o del privado, según los casos.

Es muy claro, por ejemplo, el de la libertad religiosa. En su aspecto de Derecho público se concreta en la libertad de cultos (libertad de opción religiosa) y en la supresión de toda discriminación entre los ciu- 
dadanos por razón de la religión que profesen. Como derecho de la personalidad - en el terreno del Derecho privado - se proyecta en todo tipo de situaciones jurídicas que puedan suponer lesión a los sentimientos religiosos o a cualquiera de las formas concretas de actuación derivadas de la convicción o el credo religiosos. Alcanzaría, por ejemplo, a hipótesis tan diversas como las que siguen: anulación de un matrimonio por haber ocultado un consorte su profesión de una determinada religión; anulación del contraído ignorando uno de los cónyuges que el otro estaba ya casado de acuerdo con las prescripciones de otra religión; imposición de responsabilidad al cónyuge que obliga al otro a sufrir las consecuencias del divorcio cuando esta institución ofendiese los sentimientos del consorte inocente; responsabilidad civil del profesor que ofende gravemente los sentimientos religiosos de sus alumnos; declaración del carácter abusivo de la negativa del padre, hecha bruscamente en el momento del nacimiento, de bautizar a un hijo, con ofensa a la «conciencia de una mujer cristiana en sus sentimientos más íntimos y respetables»; responsabilidad civil de quien ofende los sentimientos religiosos de un ministro de determinada religión o de un miembro de una orden religiosa; o del periódico que publica la lista de los participantes en una peregrinación; separación matrimonial basada en el hecho de haber ejercido un cónyuge violencia sobre el otro para obligarle a cambiar la religión; etc.

El profesor Jean RIVERO puso de relieve, hace 25 años, el error que se venía sufriendo cuando se pensaba que los derechos humanos sólo se proyectaban en el terreno político. Lo hizo, precisamente, al justificar el título del volumen tercero de los estudios dedicados a René CASSIN ( $L a$ protection des droits l'homme dans les rapports entre personnes privées).

Decía RIVERO: «El tema escogido para esta obra parece haber causado alguna sorpresa. Los que se preocupan de la protección de los derechos del hombre piensan sobre todo en la amenaza que sobre ellos hace pesar el poder del Estado».

Sin embargo - añadía el autor- no es éste el único riesgo que recae sobre la persona. Si el Estado puede oprimir, en efecto, es porque se halla, en relación con los que viven bajo su esfera, en posición de superioridad. A partir de esta evidencia, se impone una generalización: toda relación no igualitaria en la sociedad permite a quien domina incidir sobre los comportamientos de quien es dominado; atentar, por tanto, contra la libertad del débil. El individualismo idealista surgido de la tradición de 1789 ha creído poder eludir esta realidad, afirmando la igualdad de todos los hombres. Esto venía a constituir, desde luego, la supresión de una de las fuentes de desigualdad, la que la misma ley consagraba. Pero las que resultan de la naturaleza del hombre permanecen todavía. De la brutalidad de la supremacía física a la acción más sutil de la dominación inte- 
lectual o moral, pasando por el campo inmenso de las superioridades económicas, la lista es larga, sólo en lo que se refiere a los individuos. Si se incluyen, además, las personas jurídicas de Derecho privado, los desequilibrios se multiplican y agravan. En definitiva, pocos son quienes, en una sociedad, no dependen de otro en buena parte de su existencia.

Y más adelante, con la misma lucidez, RIVERO escribía: «La amenaza que el Estado hace pesar sobre el ejercicio de los derechos del hombre no es más que un aspecto particular de un fenómeno mucho más general: la amenaza que el fuerte despliega sobre la libertad del débil. Cierto es que la amenaza estatal es más visible y más temible, en proporción al grado de poder de coacción de que dispone el Estado; se explica que haya sido la primera en atraer la atención de los defensores de la libertad. Pero para que los derechos del hombre se vivan de verdad es necesario empeñarse en hacerlos respetar en las relaciones entre las personas privadas».

8. Otra manifestación del relieve que a la persona se le reconoce en los últimos tiempos es lo que podríamos denominar genéricamente como proceso de eliminación de discriminaciones.

Piénsese, por ejemplo, en la ya consumada desaparición de la filiación ilegítima en nuestros textos legales y, por tanto, en la desaparición de toda diversidad de trato de la persona por razón de su filiación. En España, este proceso culminó con las radicales reformas que el Código civil experimentó en 1981 para acompasar su regulación a los imperativos de la Constitución de 1978.

Dentro de este mismo capítulo tiene cabida la culminación de la equiparación jurídica de los sexos y la desaparición de toda clase de discriminaciones por su causa. Por lo que se refiere al ordenamiento español, también en 1981 se materializó este objetivo, consagrando entre otras cosas la igualdad jurídica entre marido y mujer en el régimen personal y económico del matrimonio y en la patria potestad.

9. Los niños (y en general los menores) vienen siendo destinatarios de normas tuitivas particularmente dirigidas a ellos. Al hilo de la Convención de derechos del niño, de Naciones Unidas (de 20 de noviembre de 1989), y de la Carta Europea de los derechos del niño (de 1992), casi todos los países europeos han ido dictando leyes orientadas a dotar de un nuevo régimen a instituciones clásicas, pero ahora tomando al menor como eje o centro de las mismas.

Es significativo, en España, el caso de las más recientes modificaciones del Código civil en materia de tutela (24 de octubre de 1983) y de adopción (11 de noviembre de 1987). En ellas se observa ese cambio de signo que antes he apuntado, que va mucho más allá de lo formal. El me- 
nor no es ya el objeto de las normas respectivas, sino un genuino protagonista de las instituciones reguladas.

Como última novedad tiene que ser citada la Ley orgánica de 15 de enero de 1996, de protección jurídica del menor. Su preámbulo insiste en la condición de sujeto de derechos de la persona menor de edad. Así, el concepto «ser escuchado si tuviere suficiente juicio» se ha ido trasladando a todo el ordenamiento jurídico y en todas aquellas cuestiones que le afectan. Esta concreta Ley, en particular, refleja una concepción de los menores de edad como sujetos activos, participativos y creativos, con capacidad de modificar su propio medio personal y social; de participar en la búsqueda y satisfacción de sus necesidades y en la satisfacción de las necesidades de los demás.

La misma exposición de motivos de la Ley dice: «El conocimiento científico actual nos permite concluir que no existe una diferencia tajante entre las necesidades de protección y las necesidades relacionadas con la autonomía del sujeto, sino que la mejor forma de garantizar social y jurídicamente la protección a la infancia es promover su autonomía como sujetos. De esta manera podrán ir construyendo progresivamente una percepción de control acerca de su situación personal y de su proyección de futuro. Este es el punto crítico de todos los sistemas de protección a la infancia en la actualidad. Y, por lo tanto, es el reto para todos los ordenamientos jurídicos y los dispositivos de promoción y protección de las personas menores de edad. Esta es la concepción del sujeto sobre la que descansa la presente Ley: las necesidades de los menores como eje de sus derechos y de su protección».

Ahora bien, no engañaríamos si se silenciasen las sombras que oscurecen la condición jurídica del niño.

Cuando se leen sonoras declaraciones como las que la citada Ley española proclama (por ejemplo, el derecho del menor a la libertad de ideología, conciencia y religión, o su derecho a la libertad de expresión), se tiene la sensación de que ciertas normas jurídicas son esclavas de la tendencia a lo declamatorio o platónico. Dejando aparte la circunstancia de que hablar de libertad idelógica o de libertad de expresión del menor puede llevar a situaciones de verdadera caricatura, el jurista no puede dejar de sentir alguna frustración cuando ve cómo en la civilizada Europa están siendo noticia, hoy mismo, casos de flagrante atropello a la dignidad del menor. Hace pocos días, cuando se escriben estas líneas, que Bélgica se ha visto conmocionada por la mayor manifestación popular de su historia como consecuencia del descubrimiento de una red de paidofilia contra la que los mecanismos jurídicos y procesales parecen ser insuficientes. Y en España, también en las últimas semanas, estamos viendo - con consternación - cómo las leyes penales vigentes no bastan para 
hacer frente a una operación de pornografía infantil sutilmente tramada por medio del Internet.

De otro lado, hablar de los derechos del niño puede resultar una ironía si no se afronta decididamente una política legislativa de protección de la familia. Cierto es que el menor es hoy víctima de modos de vida que el Derecho no gobierna, pero no puede dudarse que un adecuado régimen fiscal, una oportuna reglamentación del trabajo de la madre fuera del hogar, e incluso medidas legales sobre la llamada tercera edad, pueden amortiguar los desastrosos efectos (cuyas consecuencias puede lamentar la humanidad) de niños con escaso contacto con sus padres, o privados de la enriquecedora relación con los abuelos; o - por eso mismo - sometidos a un régimen escolar que quizá les proporcione «información» (en el mejor de los casos), pero que desde luego no parece el adecuado para darles «humanidad».

10. También merece mención, por cuanto constituye en muchos casos una singular valoración de la persona desde el punto de vista jurídico, el conjunto de novedades legislativas subsumibles en lo que CARBONNIER denominó, muy gráficamente, como «tránsito del hecho al Derecho».

En este punto, debe ser señalada la relevancia que hoy se atribuye en el Derecho positivo a las llamadas «uniones de hecho», esto es, a las situaciones de convivencia more uxorio, asimiladas a las matrimoniales cuando quedare acreditada una suficiente estabilidad.

11. En otro orden de cosas, pero dentro del mismo capítulo, podría darse cabida a nuevas regulaciones que, arrancando de conquistas científicas muy recientes, responden al propósito de satisfacer necesidades, intereses o simplemente deseos del individuo. Por lo que bien puede decirse que se trata de normas vinculadas al valor que la persona tiene a los ojos del Derecho.

Son ejemplo de esto último leyes como la española de 27 de octubre de 1979 sobre extracción y transplantes de órganos, la de 22 de noviembre de 1988, sobre reproducción asistida humana, la de 28 de diciembre de 1988, sobre donación y utilización de embriones y fetos humanos o de sus células, tejidos u órganos, y la de 29 de octubre de 1992, sobre regulación del tratamiento automatizado de datos de carácter personal.

En relación con las dos leyes de 1988 que acabo de citar, por cierto, es digno de resaltarse cómo con ellas se persiguen objetivos loables, porque en su raíz se halla la persona. Pero no sin dejar de advertir que también desencadenan mecanismos jurídicos potencialmente peligrosos para el individuo. Por ejemplo, como consecuencia de la degradación del concepto de padre, madre o hijo, o — lo que todavía es más grave- a causa 
de una contemplación puramente biológica y no ética del embrión o el feto humano.

Casos como los que he mencionado sirven para poner el acento en otro aspecto: el especial cuidado que el Derecho civil ha de tener para que los avances tecnológicos (en principio pensados para servir a la persona) no vayan a redundar en deterioro o incluso atropello de su dignidad. Considero que es éste uno de los grandes desafíos con los que hoy se topa el civilista, tentado, de una parte, por buscar instrumentos jurídicos para la satisfacción de las apetencias humanas; pero sujeto, de otro lado, al riesgo de que dar rienda suelta a la imaginación jurídica (valga la expresión) conduzca a desenlaces moralmente dudosos, si no grotescos e incluso inhumanos.

En este punto no puedo silenciar mi opinión. Para ello, tomo como punto de partida una afirmación que puede parecer chocante por lo que luego diré: la de que todos los deseos humanos (sin excepción) merecen mi respeto, en tanto en cuanto no pretendan causar daño a otro. Por eso, respeto el deseo de la mujer que, no pudiendo sobrellevar un embarazo, busca la «maternidad» mediante el procedimiento de utilizar una madre «portadora» (la maternidad subrogada). O el deseo de la viuda que, años después de la muerte de su marido, desea ser inseminada con su esperma, debidamente conservado hasta entonces (el famoso caso Parpalaix de Francia, hace 12 años). Respeto también el deseo de tener un hijo varón, rubio, con ojos azules y de no menos de 1,70 metros de altura en la adolescencia. Y puesto a respetar, lo hago incluso con el deseo (se me admitirá la palabra extravagancia, aunque no sea más que en su sentido etimológico) del varón que busca su propio embarazo, cosa que al parecer es posible.

Respeto también, cómo no, una ciencia que puede llegar a hacer (como se ha puesto de relieve por algún autor) que una criatura tenga cinco padres: dos padres «sociales» (la pareja comitente o que hace el encargo), dos padres genéticos y una madre subrogada que lleva a término el embarazo.

Pero salvados todos estos respetos, no puedo dejar de decir algo más.

a) Me resisto a que se afinque entre nosotros la idea de que la ley puede (o debe) satisfacer todos los propósitos, objetivos y hasta caprichos humanos. Me parece que mientras no sepamos todos que una cosa es desear algo y otra tener derecho a ello, la humanidad no va por buen camino. Ni en esta cuestión ni en otras muchas. Cualquier interés lícito puede merecer la protección de la ley, pero no a toda costa y a cualquier precio. Y desde luego, no existe el más mínimo argumento para defender que el interés por la paternidad artificial sea un derecho fundamental de la persona. 
b) La circunstancia de que el ser humano lleve a cabo incluso despropósitos en uso de su libertad, o la de que ocurran desgracias en la vida, no constituye argumento para que el Derecho legitime cualquier desenlace. La decisión de un moribundo, o un accidente, pueden hacer que un niño nazca sin padre, pero considero aberrante que la ley le «condene» a no tenerlo: como ocurre cuando se admite la fecundación de la mujer con material reproductor de su marido ya muerto.

c) Me llama la atención que las medidas jurídicas de protección del embrión se formulen de manera indirecta u oblicua, como si el embrión fuese sólo un instrumento. Creo que la lógica exigía que antes que nada se hubiese promulgado un «estatuto jurídico del embrión», porque parece claro que él es el bien más valioso de los que están en juego en todas estas prácticas.

d) Un hijo no puede ser frívolamente considerado como un «medicamento» para la «enfermedad» de una pareja ansiosa de paternidad.

e) Me asombra la desproporción entre la gran inquietud del legislador por la infertilidad de las parejas y la escasa preocupación del gobernante por sus causas. Del mismo modo que me admira que se haya dado vía libre a formas de reproducción artificial a troche y moche, sin haberse llevado a cabo estudios significativos sobre las particularidades del nacimiento y de la educación de los niños nacidos con ellas.

12. También puede ser citada —en línea parecida — la solución jurisprudencial (y en algunos casos incluso la regulación legal) de los problemas que se han dado en llamar de transexualidad, esto es, aquellos en que una persona pretende ser reconocida jurídicamente como de sexo distinto al biológico. Hay que hacer notar cómo en estos casos se suele acudir por los Tribunales a argumentos de piedad o conmiseración para con la persona que se halla en ese trance.

La sentencia del Tribunal Supremo español de 2 de julio de 1987 (la primera que accedió a la petición de un transexual) revela una cierta dosis de «compasión» hacia el demandante, al aludir al «irresistible sentimiento de pertenencia al sexo contrario, rechazo del propio y deseo obsesivo de cambiar la morfología genital». Y merece la pena recordar que la sentencia, al referirse al resultado de la intervención quirúrgica a que se había sometido el demandante, esto es, a su apariencia de hembra, dijo: «Será una ficción de hembra si se quiere, pero el Derecho también extiende su protección a las ficciones. Porque la ficción desempeña en el Derecho un papel tan importante como el de la hipótesis en las ciencias 
exactas. Una y otra son meras suposiciones que hay que admitir para legitimar determinadas consecuencias en orden a la verdad científica o de la justicia o utilidad social».

Por cierto, quiero traer a colación la sentencia de 30 de abril de 1996 del Tribunal de Justicia de las Comunidades Europeas en que se declara que el principio laboral de no discriminación es extensible a la persona que tiene intención de someterse o se ha sometido a una operación de cambio de sexo. La sentencia dice que cuando una persona en esas circunstancias es despedida por su empresa, recibe un trato desfavorable frente a las personas del sexo al que se consideraba que pertenecía antes de la citada operación.

13. Casos como los que he mencionado permiten, creo, una reflexión:

Del mismo modo que sobre las leyes de reproducción asistida o similares, no parece temerario decir que en el fondo se halla un sentido cristiano de la vida humana; en definitiva, el reconocimiento de lo mucho que necesita la persona de los demás (e incluyo el Derecho) en sus fragilidades, en sus limitaciones y en sus aspiraciones.

No obstante, cuando pensamos en los despropósitos a que algunas normas de este tipo pueden conducir, cuando vemos ciertos modos de procreación que hacen pensar que las leyes están más cerca de la zoología que de la humanidad, cuando oímos una y otra vez del «matrimonio» entre una persona y otra transexual del mismo sexo genético, o cuando los medios de comunicación nos dan cuenta del propósito de dos mujeres de tener un hijo común, quizá fuera bueno recordar una frase de CHESTERTON que me parece genial. Escribió el autor inglés que «el mundo está lleno de ideas cristianas que se han vuelto locas».

14. El Derecho de daños es terreno abonado o, si se quiere, excelente banco de pruebas para calibrar el grado de tutela dispensada a la persona por el ordenamiento civil.

a) A este respecto, y con independencia de lo que luego diré sobre leyes especiales cuyo objetivo es la defensa de ciertos valores del ser humano, creo que es interesante advertir que la persona se halla en la raíz de un fenómeno de enorme magnitud que han conocido las últimas décadas.

Me refiero a la orientación jurisprudencial que, dando un giro copernicano sobre lo que todavía a mediados de este siglo se consideraba obvio, ha sentado la doctrina de que, producido un hecho dañoso, no es la víctima la que tiene que probar la culpa del presunto responsable, sino al revés, es éste quien tiene que acreditar que empleó en su actuación toda la diligencia precisa para evitar el resultado lesivo. La presunción de culpa del agente y la 
consiguiente inversión de la carga de la prueba han adquirido carta de naturaleza en la jurisprudencia española y en la de casi todos los países europeos.

No quiero insistir en el fenómeno, por bien conocido; pero sí aventurar la tesis de que este cambio de orientación jurisprudencial tuvo, en su origen, un «móvil piadoso» de los Tribunales hacia la persona. Es innegable que hoy se aplica el nuevo criterio a todo tipo de daños, no sólo los que llamamos personales o corporales, pero el análisis de la jurisprudencia europea al respecto mueve a pensar que la médula de la nueva orientación se halla en el designio judicial de procurar la reparación del daño sufrido por el individuo en su persona. Es significativo, en el caso español, que las sentencias precursoras se dictaran en casos en que estaba en juego el interés de los más débiles, esto es, de quienes - de haberse seguido la interpretación tradicional, que por otra parte es la que fluye del texto legal civil y de las reglas procesales sobre el onus probandi- habrían visto frustrada su esperanza de ser indemnizados.

Dicho de otro modo: tengo para mí que esa revolucionaria línea jurisprudencial de que hablo, hoy ya definitivamente implantada para todo tipo de daños, tuvo su origen en el propósito de facilitar el éxito de demandas encaminadas a dar satisfacción a los daños sufridos por la persona, fueran físicos, morales, o ambos a la vez.

b) También es menester tener en cuenta que las leyes que han instaurando regímenes de responsabilidad objetiva lo han hecho, sobre todo, con el fin de reparar con tan ventajoso criterio los daños causados a la persona. No es necesario pormenorizar detalles, pues basta recordar, en lo que se refiere al Derecho español y a otros ordenamientos europeos, las disposiciones legales en materia de daños derivados de la circulación de vehículos de motor, de la navegación aérea, de la caza, etc.

Recientemente hemos tenido en la Unión Europea una expresión muy particular de este fenómeno, como consecuencia de la promulgación de la Directiva comunitaria de 25 de julio de 1985 sobre responsabilidad civil por daños causados por productos defectuosos. Tanto la propia Directiva como las leyes nacionales de transposición de la misma (la española se dictó el 6 de julio de 1994), someten al sistema de responsabilidad objetiva los daños causados a la persona, excluyendo (salvo excepciones insignificantes) los producidos sobre cosas.

c) En el mismo plano del Derecho de la responsabilidad civil, por otra parte, muchas están siendo las novedades que depara la casuística jurisprudencial. Me detengo brevemente, por ejemplo, en las ya relativamente numerosas reclamaciones judiciales derivadas de lo que podríamos llamar «un nacimiento indeseado». Se trata de las acciones, abundantísimas en Estados Unidos, que en el mundo anglosajón se conocen como wrongful conception, wrongful birth y wrongful life. Son expresio- 
nes del alto grado de sensibilidad que la persona ha llegado a tener sobre sus propios valores físicos y morales; y a la vez, de la respuesta que el Derecho da a esa sensibilidad.

Menudean ahora en Europa demandas formuladas como consecuencia del nacimiento de un hijo no deseado, pero sano, fruto de un error médico en ligaduras de trompas o vasectomías. También las demandas en que los actores, padres de una criatura nacida con una enfermedad congénita, reclaman indemnización por el hecho de que un médico erró en el diagnóstico genético prenatal, impidiendo así el recurso al aborto; o incluso porque el profesional de la Medicina no advirtió a los padres sobre la conveniencia de efectuar tal diagnóstico. Y no faltan tampoco las demandas en que quien reclama es el propio hijo, aquejado de una dolencia genética, que invoca el daño constituido por una vida doliente y atormentada; en otras palabras, que alega un supuesto «derecho a no haber nacido» $\mathrm{u}$ otro no menos original «derecho a nacer sano».

Aquí tendríamos que volver de nuevo a la frase de CHESTERTON, recordando cómo al amparo de estas acciones se han llegado a plantear en Estados Unidos pintorescas reclamaciones (los llamados pleitos «de vida insatisfactoria»), en las que el actor alega el trauma emocional resultante de haber nacido de una relación ilegítima entre los padres. De ahí a demandar por haber nacido de un determinado color, o en un hogar pobre, no hay más que un paso.

15. Todo lo que venimos diciendo en el terreno de los principios es patente también en lo que podríamos llamar la «fenomenología» del ejercicio de los derechos de la persona.

Cito, simplemente a modo de ejemplo, el impacto formidable que ha tenido en España la Ley orgánica de 5 de mayo de 1982, sobre la protección civil del derecho al honor, a la intimidad personal y familiar y a la propia imagen. La Ley ha acuñado el concepto de «intromisión ilegítima» en los derechos objeto de tutela, acudiendo a un sistema de «antijuridicidades tipificadas». Pues bien, a su amparo se han producido y se siguen produciendo abundantísimas reclamaciones judiciales, con una casuística florida y todavía hace unos pocos años inimaginable. Tan notable proliferación de demandas por atentado real o supuesto a la persona permitiría decir (por utilizar una metáfora que en el pasado apliqué a los pleitos en materia de consumo) que ha despertado la conciencia dormida del ciudadano. Es decir, que ha sido esta Ley la que ha excitado el instinto natural de autoestima y de autodefensa.

16. Creo que no me equivoco al decir que nunca como hoy ha visto la persona tan tutelados por el Derecho civil sus valores, los bienes de su esfera física y síquica, sus sentimientos e incluso sus apetencias. 
Pero, como toda moneda, ésta tiene su reverso. Un reverso en cuyo fondo quizás se encuentre lo que, según he dicho en alguna ocasión, constituye una de las características del tiempo presente y probable explicación de muchos de los conflictos jurídicos que desfilan ante nosotros.

Me refiero al hecho de que el hombre de hoy no se resigna a sufrir contrariedades sin creer (digo creerlo de verdad) que alguien tiene que responder de todas sus desventuras. No hace mucho que, ante cualquier tipo de desgracia, pensábamos que era la fatalidad o la providencia las que nos la tenían reservada. Pero hoy no. Quizá (entre otras cosas) como consecuencia de lo que nos inculca la educación que recibimos, buscamos un culpable de lo que nos aflige o, simplemente, de lo que nos incomoda o desagrada.

Vemos así cómo con frecuencia se produce una auténtica «explotación» (en el sentido económico) de los derechos de la persona. Se multiplican las demandas en busca de dinero, como dicen los autores norteamericanos. Y contemplamos - a veces atónitos - cómo se expresa la codicia al socaire de los valores más respestables del individuo. Considero que no es exagerado decir que vivimos un tiempo particularmente apto para una grosera y descarada mercantilización de los bienes de la personalidad.

Delicada y difícil es la tarea de los Tribunales para discernir debidamente y distinguir entre las demandas realmente legítimas, razonables, y las que sólo buscan una infundada o desproporcionada reparación de un valor personal que, a veces, la propia víctima ha sido la primera en depreciar o envilecer.

17. No puedo silenciar una cuestión que hoy constituye, a mi entender, una de las más delicadas, pero a la vez insoslayable, de las que rodean a la tutela jurídica del individuo.

Me refiero a la valoración del daño a la persona, esto es, a los criterios que deben presidir la actuación de los Tribunales al fijar la cuantía de las indemnizaciones por daño físico o moral. En íntima conexión con este asunto está el constituido por la definición o delimitación de los conceptos o capítulos que debe englobar la reparación del daño a la persona, del daño corporal o del daño a la salud como gustan de decir los autores italianos.

a) El problema que apunto es hoy, en mi opinión, uno de los «temas estrella» del Derecho de daños. La bibliografía sobre la materia es abundantísima. Me parece que supera a cualquier otra en la doctrina actual de la responsabilidad civil. De otro lado, la inquietud ha pasado al primer plano de las soluciones judiciales, que nunca como ahora se muestran tan inquietas por tratar de persuadir sobre el porqué de sus condenas. 
Y las leyes no han escapado a esta preocupación. Téngase presente que en España se acaba de establecer (por Ley de 8 de noviembre de 1995) una notable modificación de la vulgarmente conocida como Ley del automóvil. Se instaura en ella un régimen tasado de indemnizaciones por daños personales; esto es, una fórmula de indemnizaciones vinculantes (por medio de tablas o baremos) que los órganos judiciales no pueden superar. Por decirlo de otro modo, ha desaparecido (o por lo menos se ha amortiguado muy sensiblemente) el clásico principio de libre y discrecional valoración del daño por parte de los jueces en caso de muerte, de lesiones permanentes y de incapacidades temporales. En suma -y como ya manifesté cuando la Ley era sólo un proyecto- estamos en presencia de una auténtica «revolución» en el Derecho de la responsabilidad civil; una verdadera conmoción de principios que hasta ahora habíamos tenido por intocables.

En el mismo plano legal a que ahora me refiero, recuérdense los numerosos recursos de inconstitucionalidad planteados en Estados Unidos contra leyes estatales (o resoluciones judiciales, pero constitutivas de leading cases) que establecieron topes indemnizatorios en casos de daños a la persona y dentro de determinados sectores de actividad; por ejemplo, en supuestos de mala praxis médica.

b) Uno se siente un tanto cohibido cuando habla sobre esta materia, porque parece como si se estuviera incurriendo en una grosería o cometiendo un acto de irreverencia hacia el ser humano.

No obstante, no conviene caer en hipocresías. Decimos con frecuencia que la vida, la salud, el honor, etc., no tienen precio, pero se da la circunstancia de que todos los días los estamos sometiendo al metro pecuniario en la práctica del Derecho.

Ahora me limito a apuntar algunas reflexiones sobre la cuestión.

La reparación de un daño personal tan cualificado como es el daño moral (entendida esta expresión en su sentido más amplio, en el que tienen cabida los dolores físicos, las aflicciones, las frustraciones, los complejos y los sentimientos) no puede ser otra cosa, desde el punto de vista del Derecho, que un «consuelo», como se ha dicho en afortunada expresión. Otra, no menos afortunada, es la de que la total indemnización del daño moral constituye «una ilusión».

Parece, leyendo los clásicos franceses, que la reparación en dinero del daño moral fue un recurso al que se acudió para salvar las dificultades que a veces ofrecía la prueba del daño patrimonial sufrido por la pérdida de quien mantenía a la familia: «valorar» el dolor sufrido por los hijos era una forma de aliviar también el daño económico derivado de la muerte del padre.

Otra observación que formular es la de que la valoración del daño moral tiene que someterse a cánones o criterios de cierta objetividad. De 
no ser así, padece la igualdad ante la ley: son conocidas las a veces espectaculares diferencias entre las condenas de unos u otros Tribunales, para casos similares. También queda en entredicho el principio de seguridad jurídica, puesto que forma parte de él la posibilidad de hacer una previsión razonable de lo que los Tribunales van a decidir ante un caso determinado. Por ello mismo, aumenta artificialmente la litigiosidad, al ser difíciles los arreglos amistosos.

Yo no quiero caer en los excesos a que puede conducir un mal entendido «análisis económico del Derecho». Ni, desde luego, incurrir en el riesgo de que la cuestión que me ocupa sea una coartada o un disfraz de los intereses de los grandes poderes económicos. Pero no puedo dejar de manifestar mi convicción, argumentada en un reciente trabajo, de que en este punto es necesario poner un poco de orden. Y, desde luego, me amparo sin recato en autoridades que se han expresado en el mismo sentido: basta recordar pasajes de ilustres especialistas franceses como TUNC y VINEY.

La cuestión, como decía, está ahí y parece inexcusable abordarla seriamente. Ya sea en virtud de criterios jurisprudenciales que persuadan por su autoridad, ya por medio de normas legales.

c) Por referirme ahora a la situación en España, habrá que ver las enseñanzas que vaya a proporcionar la recién estrenada Ley de 1995. Con todo, creo que por la propia originalidad del sistema no es impertinente que exprese aquí mi impresión en torno a lo que sobre la nueva regulación se piensa en los ambientes jurídicos de mi país.

Es muy atrevido emitir juicios al respecto, pero me parece que entre los jueces el sistema no ha sido bien recibido. Es claro que en ellos existía una cierta zozobra en el sistema anterior, de libre y discrecional valoración, pero es posible que la imposición legal de indemnizaciones tasadas haya producido en muchos juzgadores la sensación de que se les recortaba la noble función de resolver conflictos. Sentimiento que, de ser así, tendría explicación, habida cuenta del derecho y del deber del juez de defender su «independencia», aunque esta palabra no se entienda en su acepción jurídica estricta.

Entre los abogados parece predominar la actitud crítica y de reparos al sistema, que acaso pudiera estar influida por la idea de que la nueva fórmula menoscaba su función de defender los intereses de sus clientes (hablo, desde luego, de clientes víctimas). Esta actitud se hallaría justificada en la medida en que el nuevo sistema reduce drásticamente la posibilidad de atender las particularidades de cada caso concreto, pues es evidente que ahora predomina el «encasillamiento» en grupos no muy numerosos. Por otro lado, parece también claro que la nueva fórmula legal ha supuesto una disminución (en términos globa- 
les) de las cuantías de las indemnizaciones percibidas. Es evidente que pueden entrar también en juego consideraciones de orden económicoprofesional.

En el mundo doctrinal aumentan las voces que manifiestan reservas (si no serias invectivas) contra el nuevo estado de cosas.

No tengo datos fiables sobre si el nuevo sistema ha conseguido uno de sus objetivos, cual es el de fomentar las soluciones transaccionales, esto es, disminuir la litigiosidad. Pero, por referencias de algún compañero especializado en la materia, parece que esa consecuencia se ha producido significativamente. Lo que también parece claro es que se ha abreviado de forma considerable la tramitación de los siniestros por parte de las compañías de seguros.

Están por ver, de otro lado, los efectos que en el ámbito macroeconómico va a producir la nueva normativa. Estoy pensando, por ejemplo, en si va o no a influir en la cuantía de las primas del seguro, tanto obligatorio como voluntario.

Yo manifiesto la opinión de que, valga la expresión, la «filosofía» del sistema es acertada. Del mismo modo, he formulado en otro lugar mis reparos hacia ciertos extremos del mismo, alguno de ellos de considerable importancia.

Esta experiencia ha convertido a España en un país verdaderamente innovador. Algunos dirán que para bien, y otros que para mal. Lo que parece evidente es que el nuevo sistema, debidamente perfeccionado, puede ser ejemplo para otros ordenamientos.

18. La historia del Derecho de la persona ofrece un panorama de vaivenes o movimientos pendulares (¿los corsi e ricorsi de que hablaba VICO?), a la vez que — contemplada en un momento dado- está plagada de claroscuros.

Mas, como decía al principio, parece que no es atrevido a decir que el Derecho de la persona en Europa, ahora, vive momentos de apogeo. Es significativo $-\mathrm{y}$ esperanzador - que los civilistas de nuestro continente hayan vuelto la mirada a quienes en el pasado, casi clamando en el desierto, reivindicaban para el Derecho civil la función de «escudo del individuo contra los abusos de poder de las agrupaciones» (así de gráfico fue BONNECASE hace ya décadas).

Al hablar de estas cuestiones no es posible silenciar un dato que estimo muy significativo. Me refiero al hecho de que cuando en el libro Intervista sul diritto privato (Padua, 1988) varios juristas italianos fueron preguntados sobre cuál habría de ser, a su juicio, la misión del Derecho privado de nuestro tiempo, la mayor parte de ellos no dudó en afirmar que su función prioritaria tenía que ser la tutela de la persona. Promovió 
aquella «entrevista» un prestigioso profesor italiano, IRTI, que por su parte, en otra obra, ha dejado escrito: «El civilista es un intelectual militante para la defensa del individuo».

Todo esto debe hacerse verdad en un continente como el nuestro, que se considera desarrollado porque ha alcanzado cotas razonables de bienestar y de educación para sus ciudadanos; pero es particularmente deseable en tantos otros lugares del planeta que no han logrado todavía el objetivo de verdadera igualdad en auténtica libertad. 